This item was submitted to Loughborough's Research Repository by the author.

Items in Figshare are protected by copyright, with all rights reserved, unless otherwise indicated.

\title{
A drag coefficient for application to the WLTP driving cycle
}

\section{PLEASE CITE THE PUBLISHED VERSION}

http://dx.doi.org/10.1177/0954407017704784

PUBLISHER

SAGE @ IMechE

\section{VERSION}

AM (Accepted Manuscript)

\section{PUBLISHER STATEMENT}

This work is made available according to the conditions of the Creative Commons Attribution-NonCommercialNoDerivatives 4.0 International (CC BY-NC-ND 4.0) licence. Full details of this licence are available at: https://creativecommons.org/licenses/by-nc-nd/4.0/

\section{LICENCE}

CC BY-NC-ND 4.0

\section{REPOSITORY RECORD}

Howell, Jeff, David C. Forbes, and Martin Passmore. 2017. "A Drag Coefficient for Application to the WLTP Driving Cycle". figshare. https://hdl.handle.net/2134/26329. 


\title{
A drag coefficient for application to the WLTP drive cycle
}

\author{
Jeff Howell, David Forbes, Martin Passmore
}

\begin{abstract}
The aerodynamic drag characteristics of a passenger car have, typically, been defined by a single parameter, the drag coefficient at zero yaw angle. While this has been acceptable in the past, it will not provide an accurate measure of the effect of aerodynamic drag on fuel consumption because the important influence of wind has been excluded. The result of using zero yaw drag coefficients will produce an under-prediction of the aerodynamic component of fuel consumption that does not reflect on-road conditions. An alternative measure of aerodynamic drag should take into account the effect of non-zero yaw angles and a variant of wind-averaged-drag is suggested as the best option. A wind-averaged-drag coefficient is usually derived for a particular vehicle speed using a representative wind speed distribution. In the particular case where the road speed distribution is specified, as for a drive cycle to determine fuel economy, a relevant drag coefficient can be derived by using a weighted road speed. An effective drag coefficient is determined with this approach for a range of cars using the proposed test cycle for the WLTP, (Worldwide Harmonised Light Vehicle Test Procedure). The wind input acting on the car has been updated for this paper using recent meteorological data and an understanding of the effect of a shear flow on the drag loading obtained from a CFD study. A terrain related wind profile, to give different mean wind velocities acting on the car has also been applied to the various phases of the drive cycle. An overall drag coefficient is derived from the work done over the full cycle. This cycle averaged drag coefficient is shown to be significantly higher than the nominal zero yaw drag coefficient.
\end{abstract}

\section{Introduction}

Fuel economy is a major concern for car owners according to surveys of customer satisfaction. In addition, they are particularly concerned that cars do not meet the fuel economies predicted by manufacturers, when driven in the real world. Most manufacturers will inform customers in the car handbook that these figures are obtained under 'ideal' conditions and warn them not to expect the same. However, the gap between test results for fuel consumption and real world performance has increased from $8 \%$ in 2001 to around $40 \%$ in 2014, (1). The difference can no longer be explained by the OEMs optimising the car performance within the flexibility allowed by the rules, or by the poor representation of real world conditions, including the exclusion of realistic wind effects, and has led to concerns over possible cheating.

The current test procedure used to derive fuel economy, in Europe, is based on the EUDC drive cycle. The EUDC drive cycle was introduced in 1996 to replace the earlier Euromix cycle which has been discredited. As current test procedures for fuel economy are considered inadequate an ambitious project is underway to replace those in use around the 
world with a common worldwide test procedure, WLTP, (Worldwide Harmonised Light Vehicle Test Procedure), based on a common test cycle, WLTC. The WLTP requires that the aerodynamic wind tunnel drag data which is applied to the WLTC must be obtained in a moving ground wind tunnel, with very low levels of freestream turbulence and at zero yaw. While the detailed requirements generate precise data, the data obtained is not necessarily what is required. The conventional 5-belt moving ground simulation does not allow the rotating wheel drag component to be measured, the low levels of turbulence potentially underestimate the car drag in the real world, and the effects of the natural wind on drag are not included. The resistance of the baseline configurations with the highest and lowest drag can, as an option, be derived from coastdown testing, which reduces issues from wheel rotation, but these have to be conducted in low wind conditions that do not represent the on-road environment. The aerodynamic drag component input to the WLTC will therefore usually be an underestimate of the aerodynamic resistance experienced by the car in the real world.

This paper does not address all the issues which lead to an underestimate of the aerodynamic drag, but only investigates the effects of including a drag component which arises from the yaw created by considering a typical distribution of the steady natural wind through application of the wind averaged drag technique. A wind averaged drag coefficient is typically determined for a fixed vehicle speed, but for application to a drive cycle a wide range of vehicle speeds must be considered.

The wide variation of drag coefficient with yaw will be shown for a range of cars of different shapes and sizes. The concept of wind averaged drag is discussed and updated with recent meteorological data and a brief study of the effect of a sheared crosswind flow on drag. The influence of vehicle speed on wind averaged drag is analysed for a range of mean wind speeds. An appropriate terrain related mean wind speed is applied to each of the four phases of the WLTP test cycle. The variation in wind averaged drag, weighted by the velocity distribution, is then determined for the whole cycle. From the power required to overcome aerodynamic drag through the cycle, an appropriate overall drag coefficient is derived.

\section{Drag coefficient at yaw}

The increase in drag coefficient with yaw can vary considerably for cars of similar shape as well as for cars of different types. Figures 1(a)and 1(b) demonstrate this for a range of cars in the MPV, small hatchback, compact SUV and saloon (notchback) car categories, which represent 1-box, 2-box and 3-box shapes. The data are obtained for 28 vehicles in the 4 categories and is the same data set as used by Howell, (2).

The principal dimensions; length, width, height and frontal area, of the cars for which aerodynamic data have been presented are given in Table A3, in the Appendix. A wide range of vehicle sizes are covered. The lengths vary from $3.85-5.07 \mathrm{~m}$, the widths from $1.68-1.90 \mathrm{~m}$, the heights from $1.39-1.86 \mathrm{~m}$ and the frontal areas from $2.06-2.80 \mathrm{~m} 2$. 

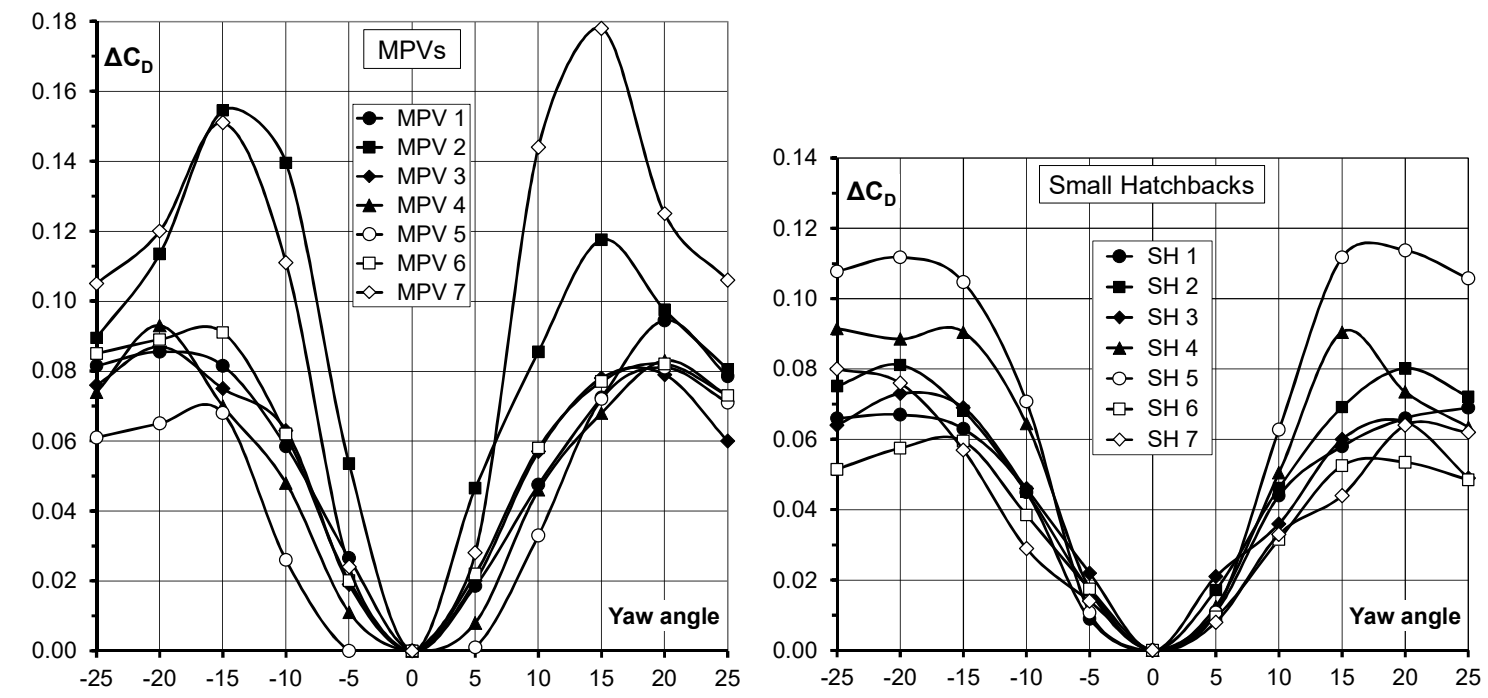

Figure 1(a) Increase of drag coefficient with yaw for 1-box MPVs (left) and 2-box small hatchbacks (right)
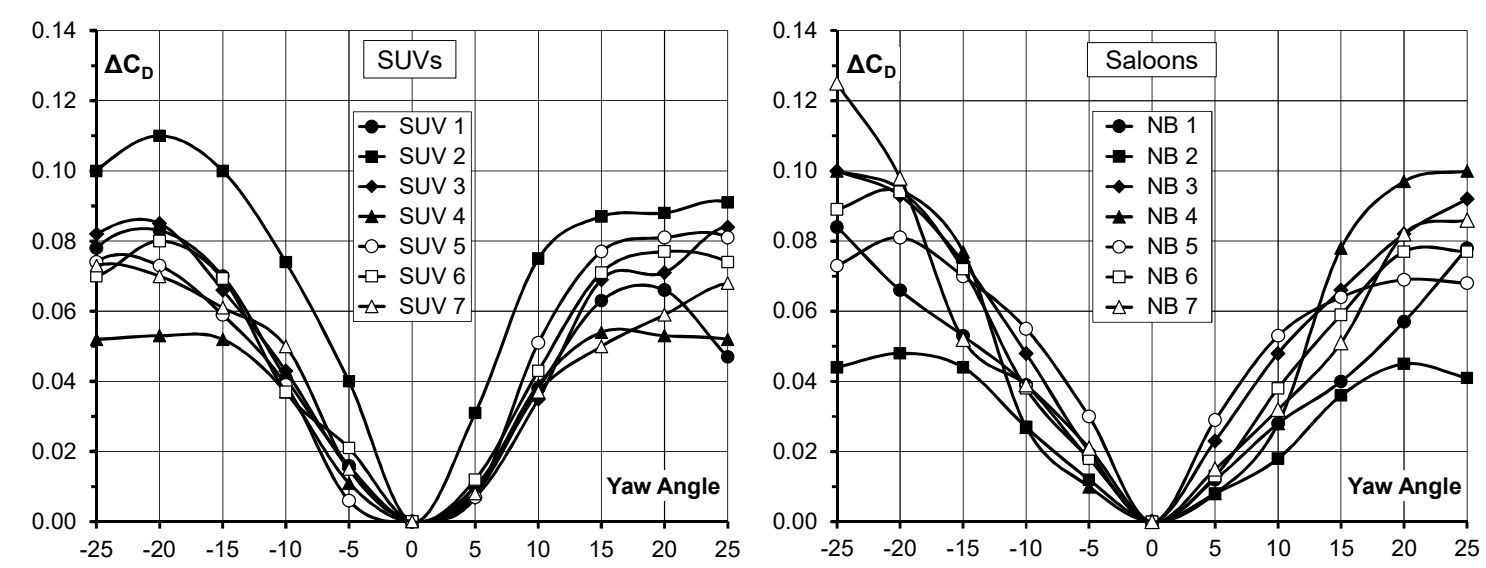

Figure 1(b) Increase of drag coefficient with yaw for 2-box SUVs (left) and 3-box Saloon and Fastbacks (right)

All the cars were tested in the MIRA full scale wind tunnel. This wind tunnel has a closed working section, $7 \mathrm{~m}$ wide and $5 \mathrm{~m}$ high, $\left(35 \mathrm{~m}^{2}\right.$ cross section) and $15 \mathrm{~m}$ long, with an open return. The wind tunnel has a fixed ground plane. The standard MIRA corrections for blockage, based on continuity, and pressure gradient have been applied. The cars were set up in the wind tunnel according to the EADE (European Aerodynamic Data Exchange) standard, with the exception that the nominal airspeed for all testing was $27 \mathrm{~m} / \mathrm{s}$.

The vehicles display a wide range of the increase in drag coefficient with yaw angle. The drag coefficient rise as measured at $10^{\circ}$ yaw, $\Delta \mathrm{C}_{\mathrm{D} 10}$, where $\Delta \mathrm{C}_{\mathrm{D} 10},=\mathrm{C}_{\mathrm{D} 10}-\mathrm{C}_{\mathrm{D} 0}$, ranges from 0.023 to 0.128 . The highest drag variation with yaw is experienced by the 1-box MPV shapes, while the lowest sensitivity to yaw is found for the 3-box notchback cars. The zero yaw drag coefficients, $\mathrm{C}_{\mathrm{D} 0}$, are given for each car in Table 1 . 
Table 1. Zero yaw drag coefficients, $\mathrm{C}_{\mathrm{D} 0}$, for all cars

\begin{tabular}{|c|c|c|c|c|c|c|c|}
\hline Car & $\mathrm{C}_{\mathrm{D} 0}$ & Car & $\mathrm{C}_{\mathrm{D} 0}$ & Car & $\mathrm{C}_{\mathrm{D} 0}$ & Car & $\mathrm{C}_{\mathrm{D} 0}$ \\
\hline MPV 1 & 0.341 & SH 1 & 0.336 & SUV 1 & 0.407 & NB 1 & 0.293 \\
\hline MPV 2 & 0.322 & SH 2 & 0.334 & SUV 2 & 0.381 & NB 2 & 0.313 \\
\hline MPV 3 & 0.320 & SH 3 & 0.333 & SUV 3 & 0.390 & NB 3 & 0.294 \\
\hline MPV 4 & 0.313 & SH 4 & 0.330 & SUV 4 & 0.394 & NB 4 & 0.301 \\
\hline MPV 5 & 0.374 & SH 5 & 0.338 & SUV 5 & 0.408 & NB 5 & 0.270 \\
\hline MPV 6 & 0.392 & SH 6 & 0.334 & SUV 6 & 0.354 & NB 6 & 0.278 \\
\hline MPV 7 & 0.353 & SH 7 & 0.323 & SUV 7 & 0.349 & NB 7 & 0.296 \\
\hline
\end{tabular}

\section{Wind averaged drag}

The drag coefficient of a passenger car almost always increases with yaw angle and therefore the zero yaw drag coefficient is, typically, the minimum drag condition. This becomes unrepresentative of the drag experienced by a car when there is a natural wind present, which is almost all the time. A wind averaged drag coefficient was proposed to account for this effect. While relatively common in the field of truck aerodynamics; see for instance; Cooper, (3), it has not been adopted for passenger cars. In part this is because trucks tend to travel long distances at relatively steady speeds and they have drag characteristics which show a very large increase at yaw.

In the past there have been reservations regarding the use of the wind averaged drag approach as it cannot be used for information on any specific journey, but represents the expected drag coefficient in an average national wind environment. These concerns, however, are less important when related to a global emission problem, such as $\mathrm{CO}_{2}$, and the analysis can be applied to all cars of a particular model distributed across a country or region, and covering many different journeys over the life of the vehicle.

In a typical case the wind averaged drag is computed for a particular car speed and accounts for the probability of wind speed and direction. The wind velocity distribution is based on averaged meteorological data for a region and an equi-probable wind direction is almost always assumed.

Various forms of the wind averaged drag coefficient exist, with different probabilities for wind speed and direction and vehicle speed. Windsor, (4), reviewed three forms of wind averaged drag and preferred the method used by MIRA, (5), (derived from Carr, (6)). The MIRA method has been adopted as a starting point for the analysis in this paper.

The wind averaged drag coefficient, $\mathrm{C}_{\mathrm{DW}}$, at a vehicle speed, $\mathrm{U}_{\mathrm{V}}$, is defined as:

$$
\mathrm{C}_{\mathrm{DW}}=(1 / \pi){ }_{0}{ }^{[180} \mathrm{C}_{\mathrm{D}}(\psi)\left(\mathrm{U}_{\mathrm{R}} / \mathrm{UV}_{\mathrm{V}}\right)^{2} \mathrm{~d} \varphi
$$


where, $C_{D}(\psi)$ is the drag coefficient at yaw angle, $\psi$, and $\varphi$ is the wind angle relative to the vehicle axis. The resultant velocity, $\mathrm{U}_{\mathrm{R}}$, and $\psi$ are functions of the car speed, $\mathrm{U}_{\mathrm{V}}$, the wind speed, $\mathrm{U}_{\mathrm{W}}$, and the wind angle, $\varphi$, as shown in Figure 2, and are given by:

$$
\begin{aligned}
\mathrm{U}_{\mathrm{R}} & =\left(\mathrm{UV}^{2}+\mathrm{UW}^{2}+2 \mathrm{UV}_{\mathrm{V}} \cos \phi\right)^{1 / 2} \\
\psi & =\tan ^{-1}\left(\mathrm{U}_{\mathrm{W}} \sin \phi /\left(\mathrm{U}_{\mathrm{V}}+\mathrm{U}_{\mathrm{W}} \cos \phi\right)\right)
\end{aligned}
$$

Wind direction is assumed to be equally probable and the probability of a certain wind speed is obtained from a weighting function.

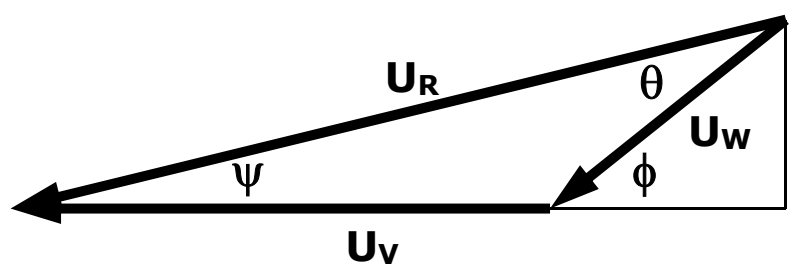

Figure 2. Velocity Diagram

As the wind data used by Carr, (6), was obtained many years ago, and the data available now is considerably more extensive, mainly due to the requirements of the wind power industry, the wind data relevant to the wind averaged drag computation has been reviewed and updated.

Equation (1) provides the wind averaged drag coefficient at a given vehicle speed, but if the distribution of vehicle speed is defined, as in the case of a particular drive cycle, it becomes possible to derive a wind averaged drag coefficient for that drive cycle. This overall drag coefficient is derived in this paper and called a cycle averaged drag coefficient.

\section{Wind environment}

A car travelling along the road is in a constantly changing environment, as a consequence of being immersed in the lowest region of the earth's atmospheric boundary layer. The natural wind is not steady in either velocity or direction. It is also turbulent and sheared.

The long term, 10 year, average annual wind speed for the UK, for $2002-2011$, according to Meteorological Office data, (7), is 8.9 knots [Note: wind speed data is still issued by the Meteorological Office in knots, (nautical miles/hour)], which is $16.5 \mathrm{~km} / \mathrm{h}$. This value, obtained at $10 \mathrm{~m}$ height, is adjusted for a sea level location and assumes an open terrain with a roughness height, $\mathrm{z}_{0}$, of $0.03 \mathrm{~m}$. This mean wind speed must be adjusted to account for a typical terrain and for a height relevant for passenger cars.

As a boundary layer flow the wind speed is zero at the ground surface and varies with height above the ground. For the lower part of the boundary layer; below $50 \mathrm{~m}$, a power law for defining the variation of wind speed with height is preferred, such that:

$$
\mathrm{U}_{\mathrm{W}}=\mathrm{U}_{\mathrm{WG}}\left(\mathrm{z} / \mathrm{Z}_{\mathrm{G}}\right)^{\alpha}
$$

where $U_{W}$ is the windspeed at a height above ground, $\mathrm{z}$, and $\mathrm{z}_{\mathrm{G}}$ is the gradient height of the atmospheric boundary layer, at which the wind velocity is $U_{W G}$ and $\alpha$ is the appropriate power. 
Typical wind velocity profiles, relevant for the study of building aerodynamics, have been defined for different terrains following Davenport, (8), and Scruton, (9), and are shown schematically in Figure 3, after Hucho, (10), with details given in Table 2. In high roughness terrains, such as town centres, this profile, near the ground, is displaced upwards by a few metres, ESDU (11), and at heights relevant to cars the wind speed is very uncertain, but takes the form shown in the detail added to Figure 3.

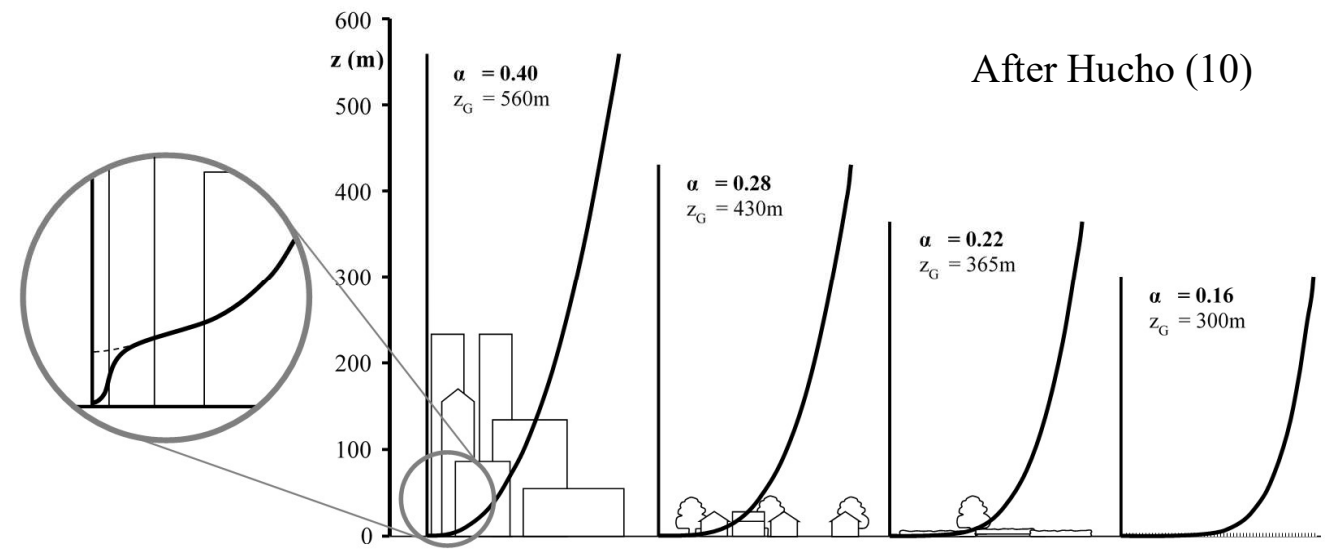

\section{Figure 3. Effect of terrain on wind velocity profiles}

It should be noted that there is a distinct lack of data for wind velocity at heights relevant for cars, (ie $\mathrm{z}<2.0 \mathrm{~m}$ ), in any conditions. Smith, (12) obtained velocity profiles over $3.0 \mathrm{~m}$ at two open terrain sites. The exponent, $\alpha$, at the two sites were approximately 0.10 and 0.18. Wind statistics from Birmingham Airport obtained at the standard height of $10 \mathrm{~m}$ were adjusted for a $2 \mathrm{~m}$ height using an exponent of 0.17 , which may explain the use of that exponent by Carr, (6). Examples of roadside wind profiles measured by Volvo in rougher terrains, presented in Götz, (13), had values of $\alpha$ from 0.22 to 0.34 . Wind data relevant for a low rise building in open terrain has been obtained by Richards et al., (14). The data compared wind energy spectra at heights of $1.0 \mathrm{~m}$ and below with $10 \mathrm{~m}$ data and showed that the von Karman spectrum does not apply close to the ground. The energy is biased to higher frequencies reflecting the increase in smaller scale eddies. In the absence of sufficient useful wind data close to the ground in roadside conditions the input required here is obtained by extrapolating the available meteorological data.

The wind speed at a different height and over a different terrain from the Meteorological Office reference data, $\left(\mathrm{z}=10 \mathrm{~m}, \alpha=0.16, \mathrm{z}_{0}=0.03\right)$ is computed, following Cooper, (15), by generating the wind speed at the gradient height for the reference case, $\left(\mathrm{z}_{\mathrm{G}}=300 \mathrm{~m}\right)$; transferring this gradient wind speed to the gradient height for the terrain required, and then calculating the wind velocity at the new height using equation (4). Table 2 also gives the ratio of the wind speed at a height of $0.6 \mathrm{~m}$ for the different terrains to the wind speed at $10 \mathrm{~m}$ height for the reference case, $(\alpha=0.16)$ to illustrate the effect of different shear flows on the wind velocity close to the ground. In the MIRA computation of wind averaged drag, (5), a height of $1.0 \mathrm{~m}$ was assumed, but this height is shown in the next section of this paper, on an Updated wind averaged drag, to be an overestimate and a more realistic typical height is considered to be approximately $0.6 \mathrm{~m}$. 
Table 2. Wind characteristics for different terrains

\begin{tabular}{|c|c|c|c|c|c|}
\cline { 2 - 6 } \multicolumn{1}{c|}{} & Terrain & $\boldsymbol{\alpha}$ & $\mathbf{z}_{\mathbf{G}}(\mathbf{m})$ & $\mathbf{z}_{\mathbf{0}}(\mathbf{m})$ & $\begin{array}{c}\mathbf{U}_{\mathbf{W}(\mathbf{0 . 0})} \\
\mathbf{U}_{\mathbf{W}(\mathbf{1 0}) \mathbf{R E F}}\end{array}$ \\
\hline 1 & Open country & 0.16 & 300 & 0.03 & 0.638 \\
\hline 2 & Rural (many hedges) & 0.22 & 365 & 0.08 & 0.421 \\
\hline 3 & Suburban & 0.28 & 430 & 0.20 & 0.273 \\
\hline 4 & City Centre & 0.40 & 560 & 1.00 & 0.112 \\
\hline
\end{tabular}

The wind profiles for these four terrain conditions, close to the ground, are shown in Figure 4. The wind velocities are relative to the mean velocity at a height of $10 \mathrm{~m}$ for the reference terrain with an exponent, $\alpha$, of 0.16 , and account for the increase in the gradient height of the boundary layer as $\alpha$ increases.

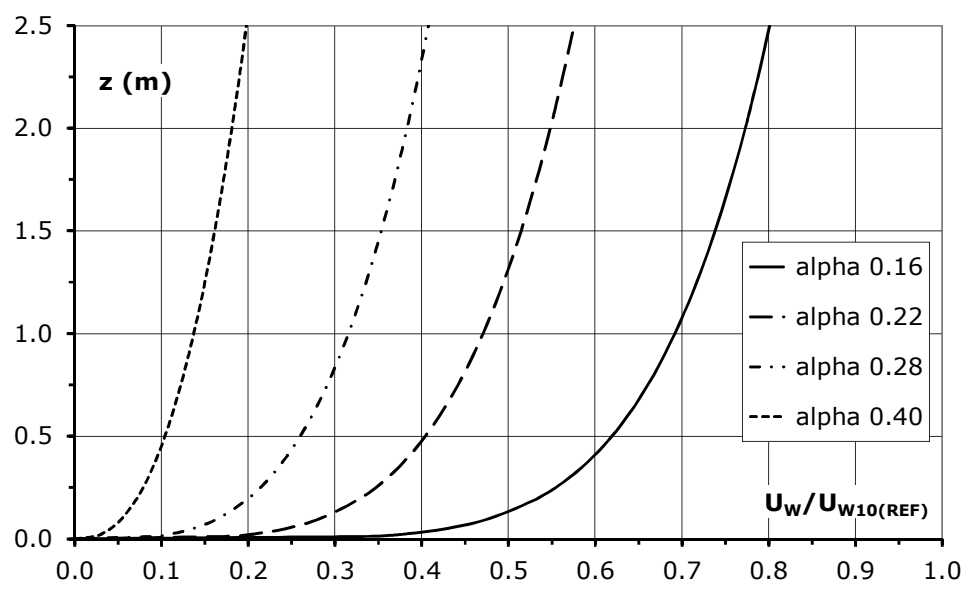

Figure 4. Wind velocity profiles near the ground

The distribution of wind speeds over time is defined closely by the Weibull function. The probability distribution function, PDF; the probability of occurrence for a particular wind speed, is given by:

$$
\mathrm{P}\left(\mathrm{U}_{\mathrm{W}}\right)=(\mathrm{k} / \mathrm{c})\left(\mathrm{UW}_{\mathrm{W}} / \mathrm{c}\right)^{\mathrm{k}-1} \exp \left(-\left(\mathrm{U}_{\mathrm{W}} / \mathrm{c}\right)^{\mathrm{k}}\right)
$$

Where $\mathrm{k}$ and $\mathrm{c}$ are the shape and scale factors respectively. It can be noted that the mean wind speed, $\mathrm{U}_{\mathrm{WM}}$ is given by:

$$
\mathrm{U}_{\mathrm{WM}}=\mathrm{c} \Gamma\left(1+\mathrm{k}^{-1}\right)
$$

where $\Gamma$ is the gamma function.

The factors $\mathrm{k}$ and $\mathrm{c}$ or $\mathrm{UWM}_{\mathrm{WM}}$ uniquely define any particular site. Früh, (16) has provided wind data from 72 sites distributed across Great Britain, (ie excluding Northern Ireland) and a summary of his data, showing $\mathrm{k}$ as a function of the mean wind velocity is presented in Figure 5. It can be seen that there is a tendency for $\mathrm{k}$ to increase with wind speed, but it is weak. 


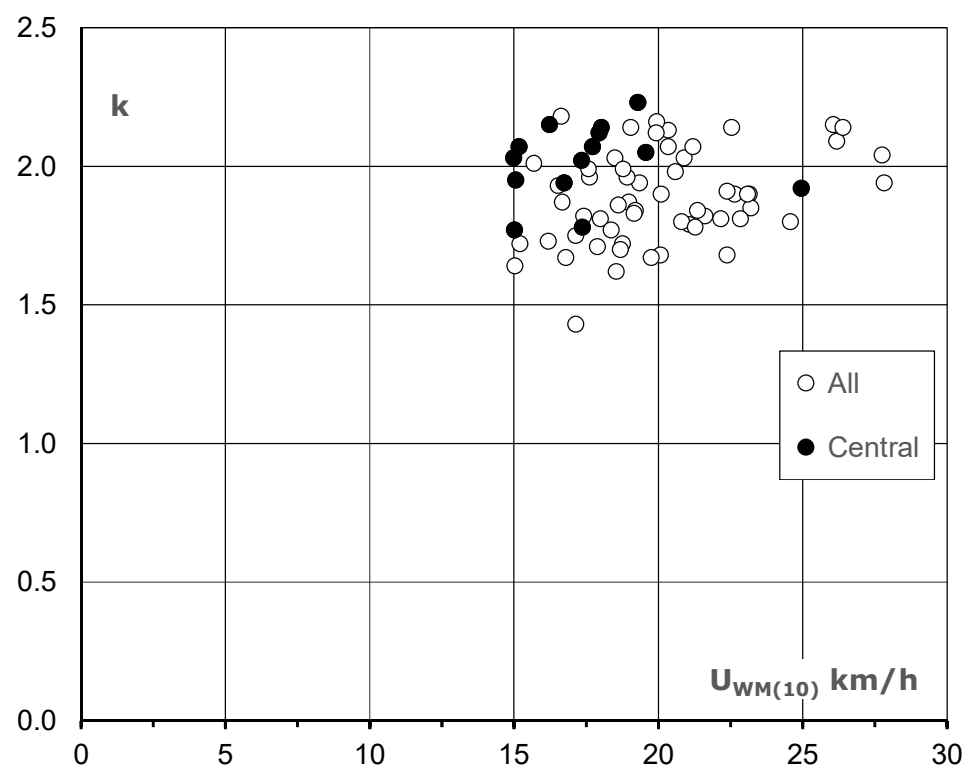

Figure 5. Weibull form parameter and mean wind speed for GB sites.

The average values over the whole country of both parameters are: $U_{\mathrm{WM}}=19.6 \mathrm{~km} / \mathrm{h}$ and $\mathrm{k}=1.91$. The main range of $\mathrm{k}$ is from 1.6 to 2.2 , with a solitary low value of 1.43 , and the mean wind speed shows a wide variation from 15.0 to $27.8 \mathrm{~km} / \mathrm{h}$. Wind speed values here are noticeably higher than the Met Office long term average, but this data is not corrected for terrain or elevation.

In this analysis the considerable variation of wind speed through the year is not relevant as the long term mean is of interest. The diurnal variation of wind speed should, however, be considered. Over land, wind speeds are higher during the day than at night. The same is true for coastal sites when the wind is from over the land. From Department of Transport data, (17), almost all vehicle journeys are undertaken between the hours of 0700 and 2200 and between these hours the mean wind speed can exceed the 24 hour average by up to $10 \%$, when averaged over the year. There is a seasonal variation in the diurnal effects, with the greatest variation in the summer months and the lowest variation in winter. An example of a 5\% variation in the average is shown in Figure 6 from Meteorological Office data, (18).

Similarly, as also shown in (17), traffic density is geographically dependent; varying significantly in different regions of the country. The highest concentrations are around the motorway networks and in particular very heavy concentrations occur in the central 'box' area defined by the cities; London, Bristol, Manchester and Leeds. The wind characteristics in this region are identified in Figure 5 as the Central data points, where it can be seen that the mean wind speed reduces to $17.5 \mathrm{~km} / \mathrm{h}$ while the average value of $\mathrm{k}$ has increased slightly to 2.02 . The range of $\mathrm{k}$ is from 1.77 to 2.23 , while the wind speed range is from 15.0 to $20.0 \mathrm{~km} / \mathrm{h}$ with one very elevated site at $25.0 \mathrm{~km} / \mathrm{h}$. 


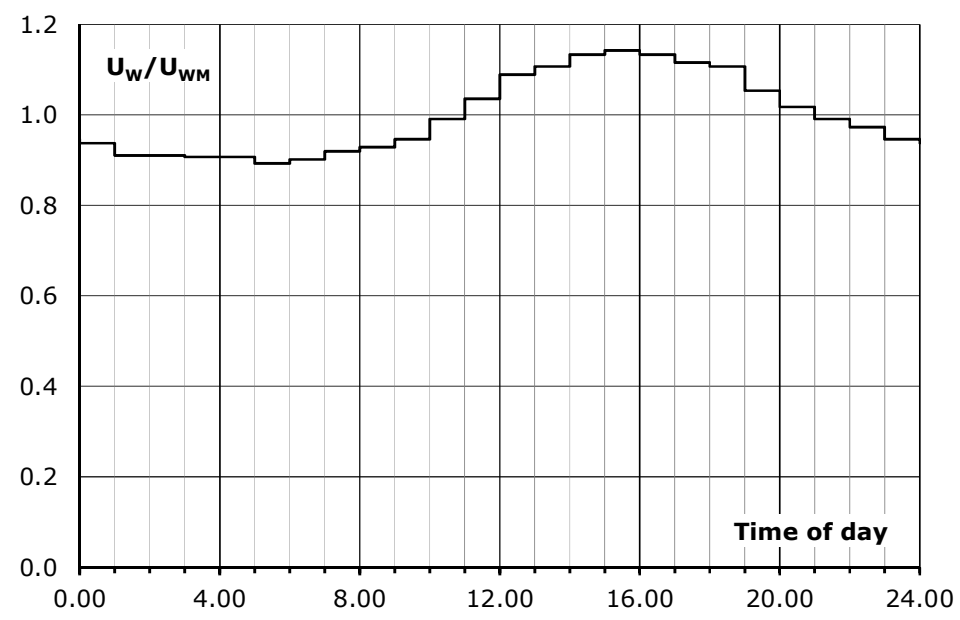

Figure 6. Typical diurnal variation in windspeed.

This wind velocity data is not adjusted and the mean wind velocity data, corrected to sea level and open terrain for the central counties of the UK is taken from (19) which gives $15.6 \mathrm{~km} / \mathrm{h}$. Mean wind speeds increase with elevation. For every $100 \mathrm{~m}$ above sea level the velocity is increased by $10 \%,(11)$. The average elevation for the motorways in this central region is approximately $100 \mathrm{~m}$.

\section{Updated wind averaged drag}

Wind averaged drag is usually obtained at a fixed vehicle speed. In the past MIRA issued wind averaged drag data in their published Surveys at vehicle speeds of 50, 70, 90, 110 and $130 \mathrm{~km} / \mathrm{h}$, with a single mean wind speed. For the purposes of this paper wind averaged drag must be calculated for a range of vehicle and mean wind speeds.

The MIRA wind data is presented as a weighted velocity distribution for a height above ground of $1.0 \mathrm{~m}$. Howell and Panigrahi, (20), have shown that the mean wind speed for this case is $8.28 \mathrm{~km} / \mathrm{h}$ and the Weibull shape factor, $\mathrm{k}=1.79$. It is now, with the passage of time, unclear how this mean wind speed was derived, but it would be consistent with a vehicle travelling in rural conditions, $(\alpha=0.21)$, and could have been considered appropriate at the time. The lower value of k obtained for the older data is partly explained by the use of cup anemometers, which tend to underestimate the contribution of low wind speeds.

Using the data currently available, as developed in the preceding section and for the purposes of this paper, the mean wind speed over a reference terrain, $(\alpha=0.16)$, at the reference height of $10 \mathrm{~m}$, adjusted for nominal elevation above sea level, $(+10 \%)$, and diurnal effects, $(+5 \%)$, is taken to be $18.1 \mathrm{~km} / \mathrm{h}$. The value of $\mathrm{k}$, the Weibull shape factor, is taken to be 2.0. This is a special case of the Weibull function known as the Rayleigh distribution. This change in the shape factor modifies the weighting distribution as used in the MIRA method. The new weighting is shown in Table 3 compared with the MIRA weighting. 
Table 3. Weighting distribution for wind speed range.

\begin{tabular}{|c|c|c|}
\hline \multirow{2}{*}{$\mathbf{U}_{\mathbf{W}} / \mathbf{U}_{\mathbf{W M}}$} & \multicolumn{2}{|c|}{ Weighting } \\
\cline { 2 - 3 } & $\begin{array}{c}\mathbf{k}=\mathbf{1 . 7 9} \\
\text { (MIRA) }\end{array}$ & $\mathbf{k}=\mathbf{2 . 0 0}$ \\
\hline $0-0.483$ & 0.210 & 0.177 \\
\hline $0.483-0.966$ & 0.330 & 0.347 \\
\hline $0.966-1.449$ & 0.250 & 0.285 \\
\hline $1.449-1.932$ & 0.130 & 0.138 \\
\hline $1.932-2.415$ & 0.055 & 0.043 \\
\hline $2.415-2.899$ & 0.020 & 0.009 \\
\hline $2.899-3.382$ & 0.005 & 0.001 \\
\hline
\end{tabular}

The wind averaged drag data presented in (20) used the MIRA weighting, $(\mathrm{k}=1.79)$ and a point of application at $1.0 \mathrm{~m}$. Computing the wind averaged drag coefficient for the same range of cars, using $\mathrm{k}=2.00$, but the same point of application, surprisingly showed an almost negligible difference. The largest difference was found to be less than 2 counts, $\left(\Delta \mathrm{C}_{\mathrm{DW}}=0.002\right)$, for the most sensitive car and at the highest wind speed. For most wind speeds and vehicles the difference was less than 1 count. An assessment was also made of the weighting distribution to see if the wind averaged drag was influenced by increasing the number of steps in the distribution. For the particular vehicle investigated, increasing the steps to 26 , from 7 in the MIRA method, for a bin size of $1 \mathrm{~km} / \mathrm{h}$, changed the wind averaged drag coefficient by less than 1 count.

The wind averaged drag coefficient has been computed for a range of vehicles, as follows. The drag characteristics for each vehicle at yaw are made symmetrical by averaging the drag coefficient at each \pm yaw angle. This is not analytically essential, but it avoids taking the integration limits in equation (1) to $\pm 180^{\circ}$. Curve fitting of the drag data is done in two steps; a $4^{\text {th }}$ order even polynomial is fitted to the data from $0^{\circ}$ to 5 or $10^{\circ}$ and from 5 or $10^{\circ}$ to $25^{\circ}$ a $4^{\text {th }}$ order polynomial is applied. With such high order polynomials any extrapolation is suspect, but the effect on the overall wind average drag from higher yaw angles is negligible. The wind averaged drag coefficient, $\mathrm{C}_{\mathrm{DW}}$, is calculated using equation (1) and as detailed by Windsor, (4). This assumes that all wind angles are equally probable, but the modified weighted wind velocity distribution, given above, is applied. $\mathrm{C}_{\mathrm{DW}}$ is calculated for vehicle speeds of 15,30 and $60 \mathrm{~m} / \mathrm{s},(54,108$ and $216 \mathrm{~km} / \mathrm{h})$, and mean wind speeds from 2.1 to $12.5 \mathrm{~km} / \mathrm{h}$ to provide a range of values for the wind speed to vehicle speed ratio, $\mathrm{U}_{\mathrm{WM}} / \mathrm{U}_{\mathrm{V}}$.

For any particular vehicle the wind averaged drag is found to be a unique function of $\mathrm{U}_{\mathrm{WM}} / \mathrm{UV}_{\mathrm{V}}$, although technically this only applies if a constant weighting distribution for $\mathrm{U}_{\mathrm{W}} / \mathrm{U}_{\mathrm{WM}}$ is applied. Typical examples for 4 different vehicles are shown in Figure 7, but all vehicles show a similar variation. When the mean wind speed is zero the wind averaged drag coefficient is equal to the zero yaw drag coefficient, $\mathrm{C}_{\mathrm{D} 0}$. At higher wind speed ratios the wind averaged drag increases approximately linearly. 


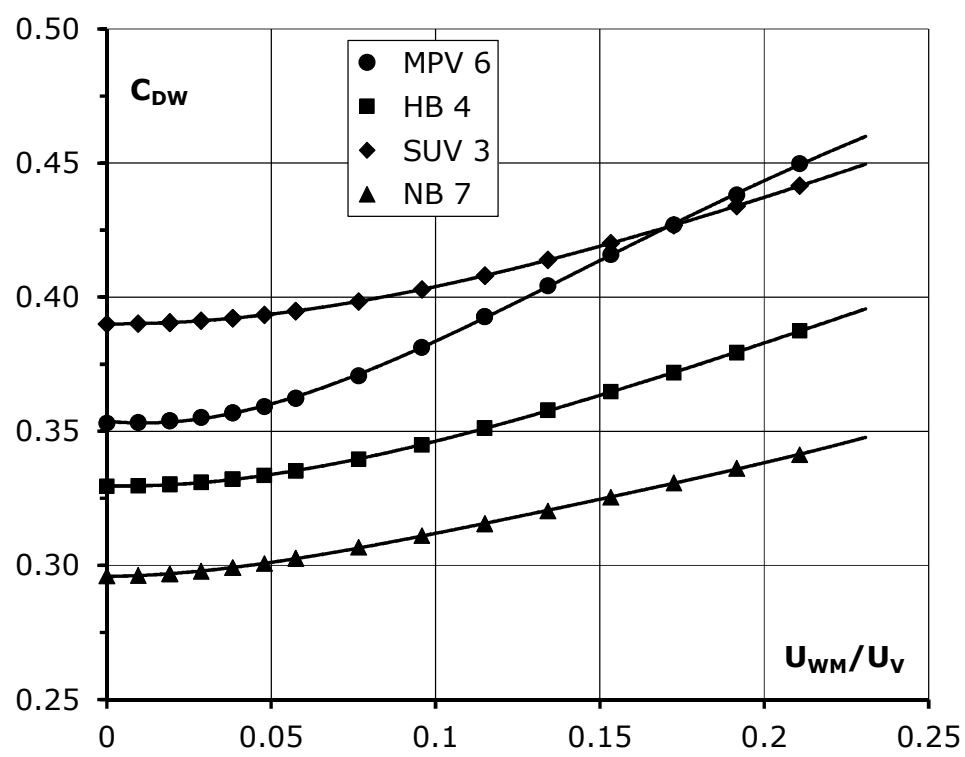

Figure 7. Variation of $\mathrm{C}_{\mathrm{DW}}$ with $\mathrm{U}_{\mathrm{WM}} / \mathrm{U}_{\mathrm{V}}$ for different vehicle types.

In the MIRA method it is assumed that the shear flow wind input is equivalent to a uniform crosswind, where the magnitude of the crosswind is equal to the sheared wind velocity at a fixed height above the ground. This height was chosen to be $1.0 \mathrm{~m}$ and was applied to all cars, but the justification is now unknown. (Note: A similar fixed point of application was used by Cooper, (15), for trucks; in this case the height was $3.0 \mathrm{~m}$ ).

Recent studies at Loughborough University by Forbes, to be published, (21), has provided a potential solution to this uncertainty. Using CFD, the steady state drag coefficient has been computed for both fastback and estate, (squareback), vehicle shapes in a crosswind. The applied crosswind was modelled with a uniform velocity profile and a shear profile, with exponent, $\alpha=0.16$. For comparison the shear flow input had the same mass flow over the height of the car as in the uniform, unsheared, crosswind case. The drag and the vertical distribution of drag were found to be almost identical in the two cases. Table 4 shows the drag coefficients for both car configurations at zero yaw and at $10^{\circ}$ yaw in a uniform and sheared crosswind. The yaw angle for the sheared crosswind flow is defined by the mean crosswind velocity over the car height. The drag loading in the vertical plane is shown in Figure 8 for the two crosswind cases and at zero yaw for the fastback shape.

Table 4. Drag coefficients in a uniform and sheared crosswind flow.

\begin{tabular}{|c|c|c|c|}
\hline \multirow{2}{*}{ Car } & \multirow{2}{*}{$\mathbf{C}_{\text {D0 }}$} & \multicolumn{2}{|c|}{$\mathbf{C}_{\text {D10 }}$} \\
\cline { 3 - 4 } & & Shear & Uniform \\
\hline Estate & 0.309 & 0.357 & 0.358 \\
\hline Fastback & 0.257 & 0.335 & 0.333 \\
\hline
\end{tabular}

For equal mass flow over the height of the car the mean velocity is the shear flow velocity at a height of 0.4 times the height of the car, approximately, which suggests that this is the 
height at which the crosswind velocity acting on the vehicle in a sheared flow is determined.

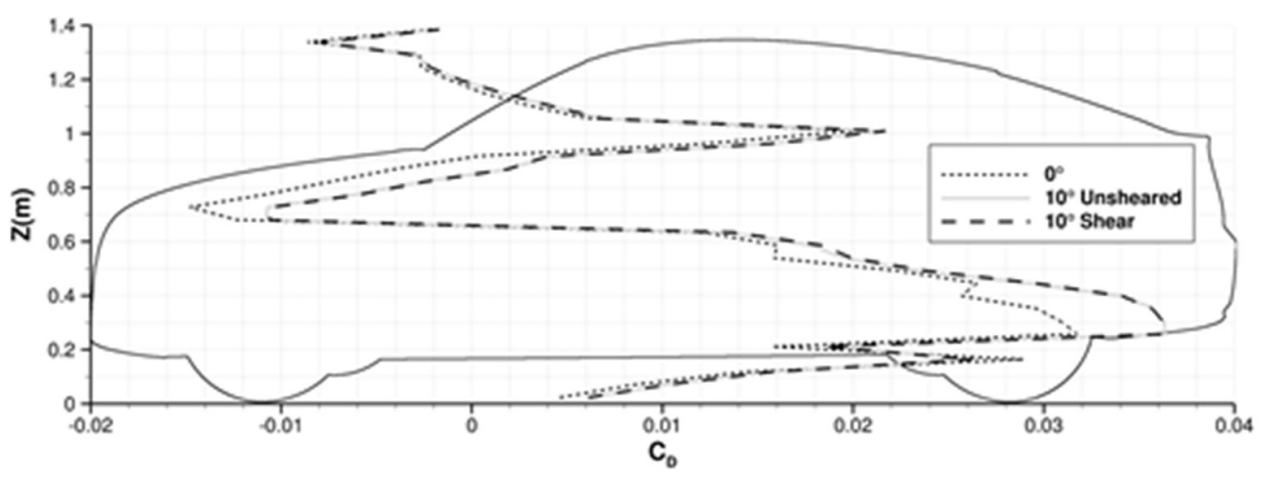

Figure 8. Drag distribution at $10^{\circ}$ yaw, with and without shear.

While this study has only been conducted for two vehicle types, one exponent and one yaw angle, it is felt that the result has more general application to other vehicle types. The wind velocity input for each vehicle is then taken to be the velocity at $40 \%$ of the vehicle height and will be different for each car. For a typical vehicle height of $1.5 \mathrm{~m}$ this height is $0.6 \mathrm{~m}$. It does not vary significantly with increasing shear exponent.

Using the mean wind speed of $18.1 \mathrm{~km} / \mathrm{h}$ for open country terrain at $10 \mathrm{~m}$, established at the start of this section, the mean wind speeds for the four terrain conditions of Table 2 at $0.6 \mathrm{~m}$ are: City centre; $2.02 \mathrm{~km} / \mathrm{h}$, Suburban; $4.95 \mathrm{~km} / \mathrm{h}$, rural; $7.61 \mathrm{~km} / \mathrm{h}$, open country; $11.54 \mathrm{~km} / \mathrm{h}$.

\section{Application to WLTC}

The Worldwide Harmonised Light Vehicle Test Cycle, (WLTC), is the test cycle that supports WLTP and is employed to generate fuel economy and emissions data. The vehicle speed is shown in Figure 9 as a function of time. The WLTC is divided into four parts defined as Low, Medium, High and Extra High speed phases. These divisions were originally described as Urban, Rural, and Motorway phases, (with the Motorway section divided into two high speed sections). The basic speed details for each phase are summarised in Table 5. The effects of stops are ignored.

Table 5. Speed details for the WLTC phases.

\begin{tabular}{|c|c|c|}
\hline Phase & $\begin{array}{c}\text { Average speed } \\
(\mathbf{k m} / \mathbf{h})\end{array}$ & $\begin{array}{c}\text { Maximum speed } \\
(\mathbf{k m} / \mathbf{h})\end{array}$ \\
\hline Low & 25.7 & 56.5 \\
\hline Medium & 44.5 & 76.6 \\
\hline High & 60.8 & 97.4 \\
\hline Extra high & 94.0 & 131.3 \\
\hline Overall & 53.8 & \\
\hline
\end{tabular}




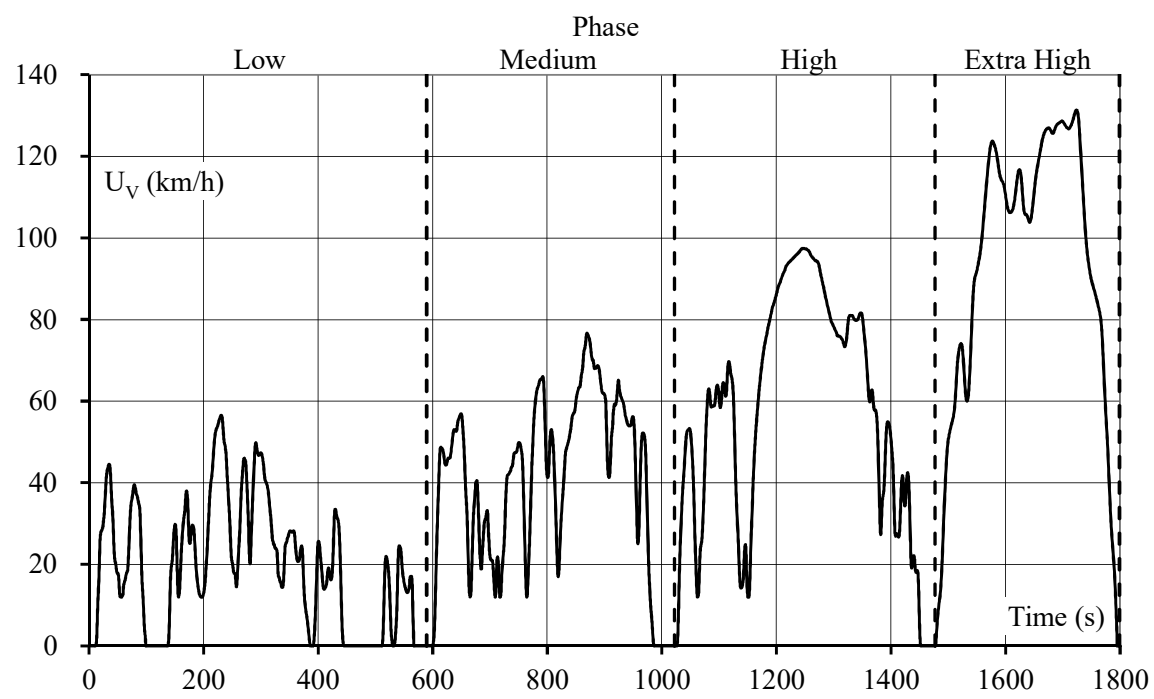

Figure 9. Worldwide Harmonised Light Vehicle Test Cycle

The vehicle speed distribution, obtained from the time spent at any given speed as a ratio of the total cycle time, excluding stops, for each phase of the cycle is shown in Figure 10, left axis. The car speed data is taken in steps, bins, of $5 \mathrm{~km} / \mathrm{h}$.

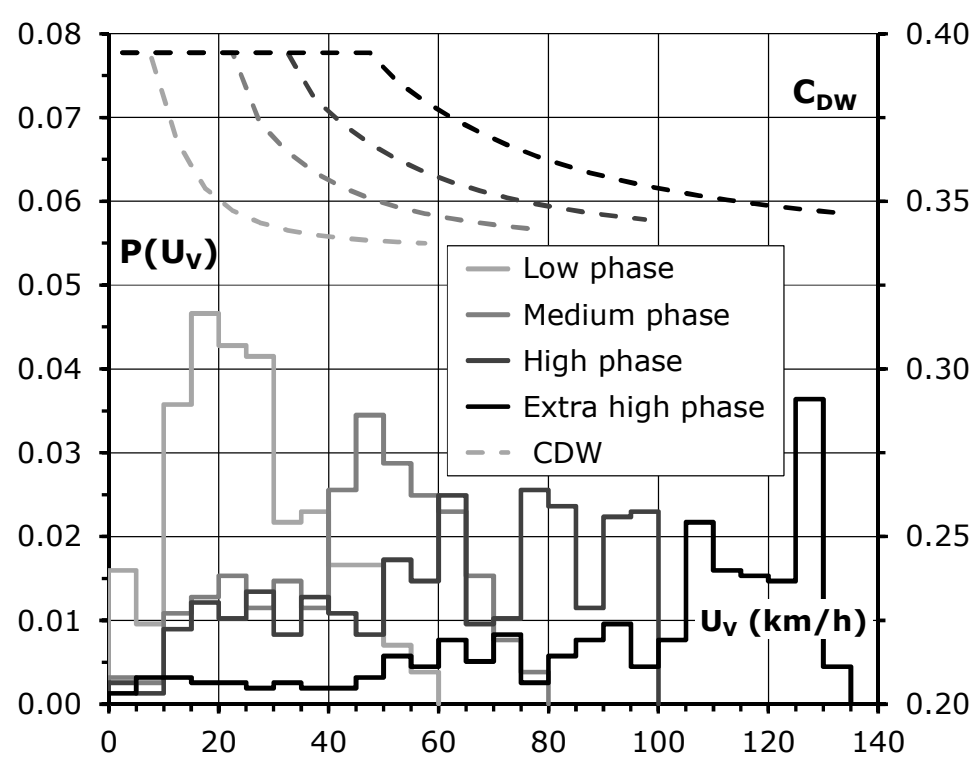

Figure 10. WLTC velocity distribution and $C_{D W}$

For the purpose of calculating the wind averaged drag, it is assumed that each phase operates in broadly different terrains. Thus the low speed section is predominantly city centre driving, while the extra high speed phase will be mainly in open country. For the purposes of this paper the terrain categories 1 to 4 from Table 1 are applied to the four phases of the drive cycle, and therefore a mean wind velocity can be ascribed for each 
phase. As the wind averaged drag coefficient, $C_{D W}$, is simply a function of $U_{W M} / U_{V}$, the variation of $\mathrm{C}_{\mathrm{DW}}$ through the drive cycle can be obtained, and an example for a small hatchback is shown for the 4 phases in Figure 10, right axis.

The low wind speeds in the low speed phase can still generate large yaw angles, because the vehicle speed is low, but the aerodynamic resistance is also low. For this reason and because of the uncertainty in the flow near to ground, as discussed in the section on the wind environment, the drag coefficient is taken to be the drag coefficient at zero yaw. In the other phases where the vehicle speed is low and the ratio $U_{W M} / U_{V}$ is higher than 0.3 the wind averaged drag coefficient is capped at the value for $U_{W M} / U_{V}=0.3$ to avoid uncertainties from over-extrapolation. This cap is arbitrary, but adjusting the value from 0.25 to 0.5 produced a negligible variation in the overall cycle averaged drag coefficient.

For the purposes of this paper the power required to overcome aerodynamic drag through the test cycle must be evaluated. The power required, $\mathrm{P}_{\mathrm{A}}$, is given by:

$$
\mathrm{P}_{\mathrm{A}}=\rho \mathrm{UV}^{3} \mathrm{AC}_{\mathrm{DW}} / 2
$$

where $\rho$ is the air density and A is the car frontal area. The distribution of the power required, as a function of the car velocity is shown in Figure 11 for the four phases of the WLTC.

To determine a cycle averaged drag coefficient the work done over the whole cycle with the wind averaged drag coefficient, $C_{D W}$, varying with the velocity ratio, $U_{W M} / U_{V}$, is equated with the work done when the drag coefficient remains constant. This constant drag coefficient is denoted by $\mathrm{C}_{\mathrm{DWC}}$, the cycle averaged drag coefficient. Thus:

$$
C_{\text {DWC }}=\int^{T} C_{D W} U_{V^{3}} d t / \int^{T} U_{V^{3}} d t
$$

where $\mathrm{T}$ is the total time for the four phases of the test cycle, excluding the periods when the car is stationary.

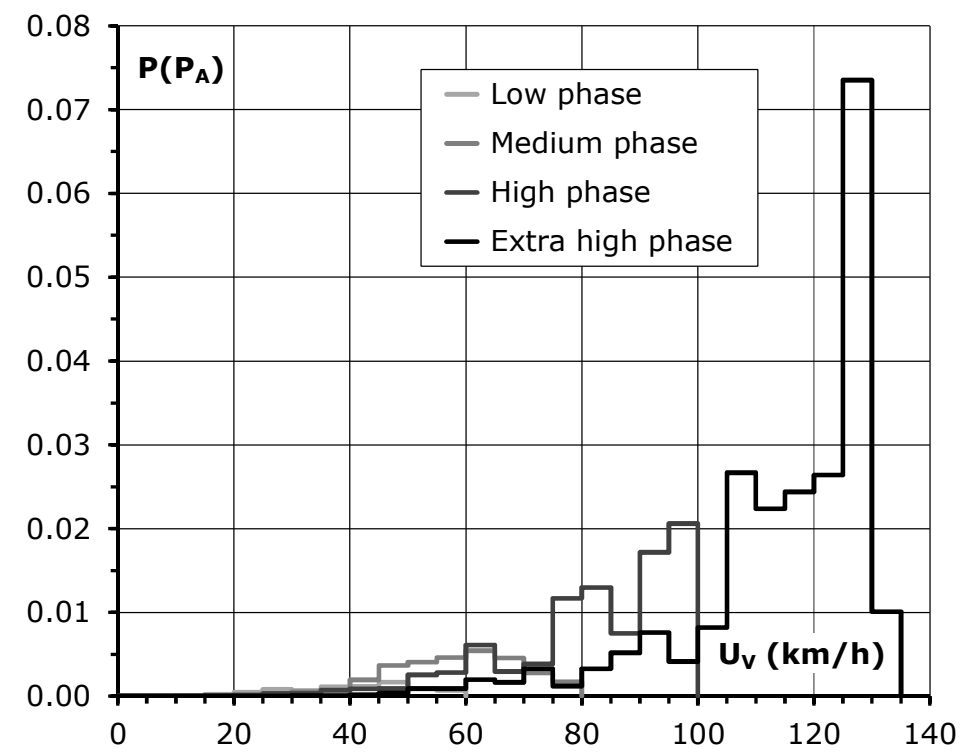

Figure 11. Distribution of drag power over the cycle. 


\section{Cycle averaged drag coefficient}

Following the process described in the preceding section the WLTC cycle averaged drag coefficient has been determined for each car in the 28 vehicle dataset representing four vehicle categories; 1-box MPVs, 2-box hatchbacks and compact SUVs, and 3-box notchand fastback shapes. The values are plotted as a function of the zero yaw drag coefficient in Figure 12.

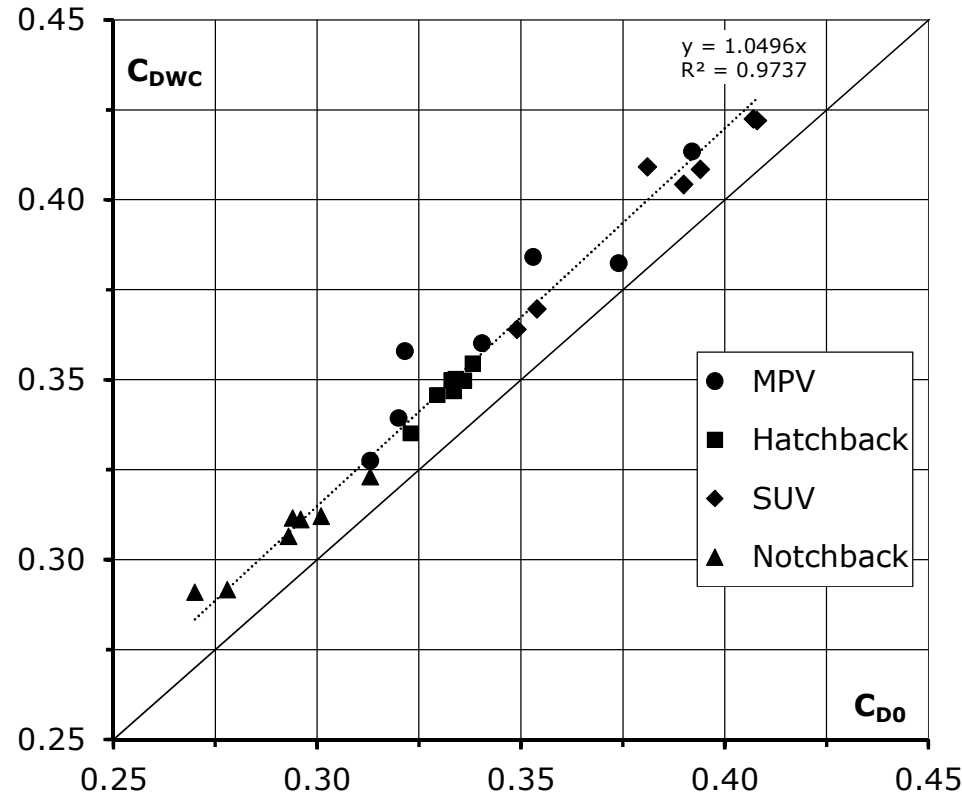

\section{Figure 12. Cycle averaged drag coefficient v zero yaw drag coefficient.}

It can be seen that there is little correlation between the two. $\mathrm{C}_{\mathrm{DWC}}$ is typically about $5 \%$ higher than the zero yaw drag coefficient, but in the worst case it is $11.4 \%$ higher, while in the best case it differs only by $2.2 \%$. In both cases the vehicle is an MPV.

The increase in the computed cycle averaged drag coefficient from the zero yaw drag coefficient, $\Delta \mathrm{C}_{\mathrm{DWC}}=\mathrm{C}_{\mathrm{DWC}}-\mathrm{C}_{\mathrm{DO}}$, is plotted as a function of the rise in the drag coefficient at $10^{\circ}$ yaw, $\Delta \mathrm{C}_{\mathrm{D} 10}=\mathrm{C}_{\mathrm{D} 10}-\mathrm{C}_{\mathrm{DO}}$, as measured in the wind tunnel, in Figure 13.

Several OEMs use a similar drag coefficient increase as a target measure of aerodynamic drag in the real world, but it is given much less significance than the zero yaw drag coefficient. The correlation here is not good but it shows a general trend that the increase in the cycle averaged drag tends to increase as the drag rise at yaw increases. In this data set there is a fourfold increase in $\Delta \mathrm{C}_{\mathrm{DWC}}$ between those cars with the lowest and highest sensitivity of drag to yaw. 


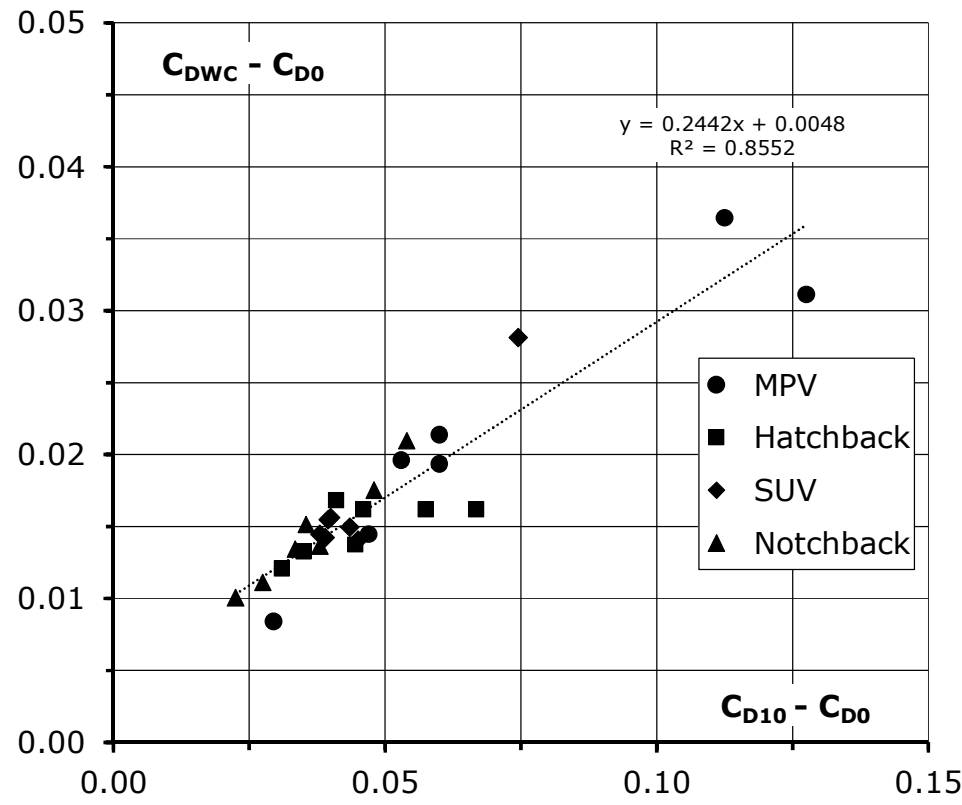

Figure 13. Increase of cycle averaged drag coefficient v drag coefficient rise at yaw.

From a breakdown of the four phases of the drive cycle, the contribution of each phase to the overall aerodynamic work done over the cycle can be obtained, which is the same as the contribution of each phase to the cycle averaged drag coefficient. The breakdown is essentially identical for all the cars investigated and is shown in Table 6.

\section{Table 6. Breakdown of phase contribution to overall drag.}

\begin{tabular}{|c|c|}
\hline Phase & Contribution \\
\hline Low & 0.02 \\
\hline Medium & 0.09 \\
\hline High & 0.26 \\
\hline Extra high & 0.63 \\
\hline Overall & 1.00 \\
\hline
\end{tabular}

Almost $90 \%$ of the drag comes from the high speed and the extra high speed phases. The small contribution from the low and medium speed phases suggests that the wind speed characteristics for these do not need to be very accurately defined, whereas much greater precision is required for the high speed phases. A corollary of this is that the drive cycle in the high speed phase must be appropriate and carefully defined for the drag contribution to be accurate. 


\section{Discussion}

\section{Weibull shape factor}

The Weibull shape factor, $\mathrm{k}=2.0$, used in this paper and derived from a wide range of measurement sites across Great Britain has been changed from that used in the MIRA method, which was $\mathrm{k}=1.79$. It has been found however that this change has almost no effect on the wind averaged drag coefficient throughout the range of wind and vehicle speeds of interest in this paper. This seems a surprising result as the peak in the wind distribution moves to a noticeably higher wind speed for the same mean wind speed. The weighting employed here follows the MIRA method and has seven wind speed inputs, (bins), to represent the Weibull wind distribution. The insensitivity of the wind averaged drag coefficient to the value of $\mathrm{k}$ resolves one uncertainty. Some authorities in the field of wind power claim that $\mathrm{k}$ changes significantly with height, although most do not consider the effect. It can be ignored for this analysis.

\section{Effect of reference wind speed}

The wind averaged drag coefficient and, as a consequence, the cycle averaged drag coefficient is, however, sensitive to the choice of wind speed. While the long term mean value of the natural wind at $10 \mathrm{~m}$ is reasonably well understood, the knowledge of shear flows in the road environment experienced by passenger cars is almost non-existent and the choice of terrain applicable to the different phases of the test cycle, as used in this analysis, must be considered arbitrary. While the wind data used here is based on UK meteorological data, a similar mean wind speed is found across most of northern Europe. In southern Europe however wind speeds tend to be lower.

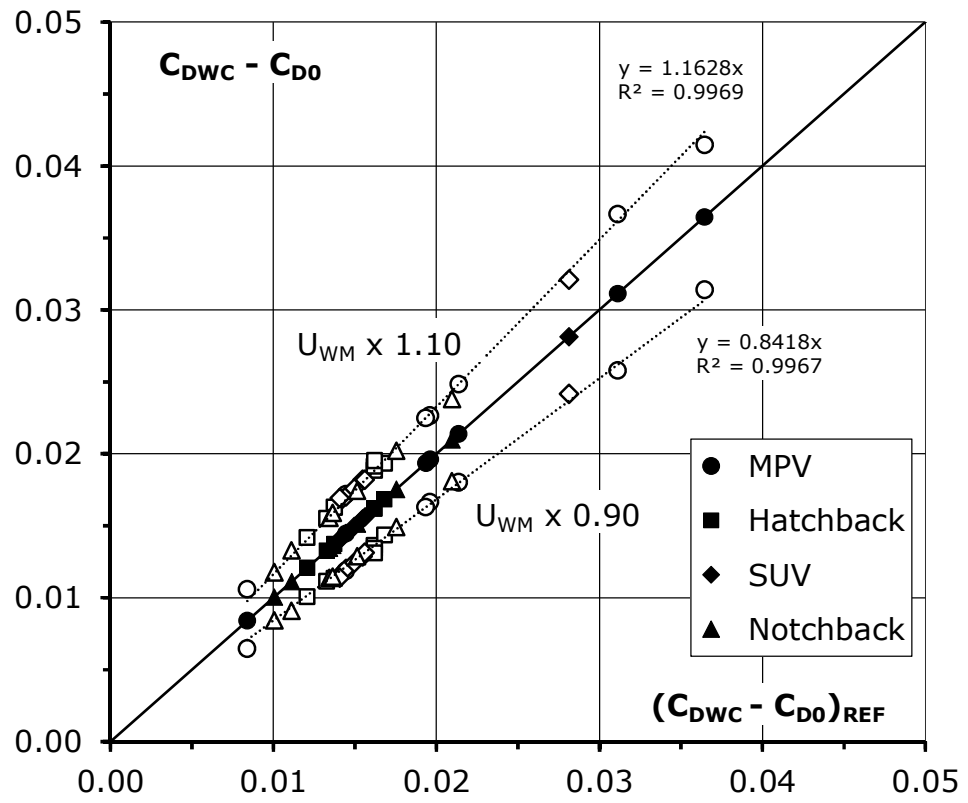

Figure 14. Change of cycle averaged drag coefficient with mean wind speed. 
There is, therefore, considerable uncertainty about the correct wind speed values to apply in this analysis. However, the sensitivity of the cycle averaged drag coefficient to changes in mean wind speed can be explored. The effect of a $\pm 10 \%$ change in reference mean wind speed, which modifies the wind speed over the whole cycle, is shown in Figure 14. A 10\% change in mean wind speed results in an approximately $16 \%$ change in the increase of the cycle averaged drag coefficient over the zero yaw drag coefficient. Over the full range of vehicles in the data set this variation represents a change in drag coefficient of between 2 and 6 counts, $\left(\Delta C_{D}=0.002\right.$ to 0.006$)$, for cars with the lowest and highest wind averaged drag coefficients, respectively.

\section{Drag input considerations}

The aerodynamic data used in this analysis are based on wind tunnel measurements, where the flow is uniform and low turbulence. In the real world the effects of the natural wind introduce unsteadiness. At the low frequency end of the spectrum the flow can be treated as quasi steady, while changing in both velocity and direction. It has been shown theoretically by Howell, (22), that this can introduce a significant unsteady drag component, which is dependent on the drag rise at yaw. The high frequency end of the flow unsteadiness spectrum can be considered as free stream turbulence, FST. In a review of the literature on FST relevant to road vehicles, Howell et al, (23), showed that, in general, the zero yaw drag coefficient is increased by FST and the effect is vehicle specific, but there is almost no published data on the effects of FST on drag at yaw for car shapes.

\section{Simplifications}

The computation to derive the cycle averaged drag coefficient, $\mathrm{C}_{\mathrm{DWC}}$, is fairly complex, but some simplifications can be made. If, instead of a variable height, ( $0.4 \mathrm{x}$ car height), for the calculation of wind speed, a fixed height of $0.6 \mathrm{~m}$ is used the deviation from the correct result is less than 1 count, $\left(\Delta C_{D}=0.001\right)$, for all the vehicles in the dataset. It should be noted that this height is significantly less than the $1.0 \mathrm{~m}$ used in the MIRA method.

An almost identical result for the cycle averaged drag coefficient is found from the wind averaged drag coefficient obtained at a single fixed wind to vehicle speed ratio, $\mathrm{U}_{\mathrm{WM}} / \mathrm{U}_{\mathrm{V}}$ $=0.101$. The difference with the correct result is also less than 1 count for all the cars investigated here. The cycle averaged drag coefficient can, therefore, be derived with sufficient accuracy by using the MIRA method with the unmodified wind distribution and a vehicle speed of $82.0 \mathrm{~km} / \mathrm{h}$.

The wind tunnel data used as input were obtained at yaw angles up to $\pm 30^{\circ}$, at $5^{\circ}$ intervals. These high yaw angles are required to produce accurate wind averaged drag coefficients at high wind to road speed ratios, but they make a negligible contribution to the overall cycle averaged drag coefficient. It can be shown that the value of $\mathrm{C}_{\mathrm{DWC}}$ is unchanged (to 4 decimal places) by setting the drag coefficient at yaw angles greater than $25^{\circ}$ to the $C_{D}$ value at $25^{\circ}$.

This is confirmed by a regression analysis that has been applied to the wind tunnel derived data which shows that the cycle averaged drag coefficient can be given by:

$$
\mathrm{C}_{\mathrm{DWC}}=0.530 \mathrm{C}_{\mathrm{D} 0}+0.345 \mathrm{C}_{\mathrm{D} 5}+0.130 \mathrm{C}_{\mathrm{D} 10}+0.007 \mathrm{C}_{\mathrm{D} 15}
$$


where $\mathrm{C}_{\mathrm{D} \psi}$ denotes the drag coefficient obtained in the wind tunnel at each yaw angle, $\psi$, from $0^{\circ}$ to $15^{\circ}$. There is no physical reality to this expression, but the agreement is good with the difference from the derived values, again, always less than 1 count. It can be considered as an engineering tool for determination of the proposed cycle averaged drag coefficient.

\section{Drag measurement implications}

The principal component is the zero yaw drag coefficient, but the $C_{D}$ at $5^{\circ}$ yaw is almost as significant. The input from higher yaw angles have a diminishing influence. The importance of the drag coefficient at these small yaw angles suggests that drag data should be obtained between $0^{\circ}$ and $5^{\circ}$ and it can be noted that Windsor, (4), recommended measuring drag at $1^{\circ}$ intervals between $\pm 5^{\circ}$.

A further implication is that the aerodynamics development engineer should give as much effort to reducing the drag coefficient at yaw angles up to $10^{\circ}$, or even $15^{\circ}$, as is currently devoted to reducing the zero yaw drag coefficient.

An increase in the applied drag coefficient to account for the effects of a natural wind, as proposed here, will have an impact on overall fuel economy, but the effect will be small for many cars. Typically the drag is increased by 5\%, which would increase fuel consumption by approximately $1 \%$. However, for cars which are sensitive to yaw, where, from examples given in this paper, the drag increase can approach $12 \%$, the increase in fuel consumption can be expected to exceed $2 \%$, which cannot be ignored. It is important that all vehicle characteristics which influence fuel economy are represented appropriately.

\section{Conclusions}

This paper is an attempt to generate a drag coefficient for application to the Worldwide Harmonised Light Vehicle Test Cycle, WLTC, using the principles of wind averaged drag.

The wind averaged drag coefficient, for a given vehicle, is shown to be a unique function of the ratio of wind speed to vehicle speed if the wind speeds have the same velocity distribution.

A typical terrain is ascribed to each phase of the drive cycle so that an appropriate mean wind speed can be defined. The variation of wind averaged drag through the cycle can be calculated.

The drag on a car in a sheared crosswind is approximately the same as in a uniform crosswind where the mass flow over the height of the car is the same.

As the vehicle velocity distribution is known for the drive cycle the work done in overcoming aerodynamic drag can be determined.

The effective cycle averaged drag coefficient is derived by equating the work done over the cycle with a variable and a fixed wind averaged drag coefficient.

The cycle averaged drag coefficient is substantially higher than the zero yaw drag coefficient in all cases investigated, but the increase is vehicle specific. The input data were 
derived from steady state wind tunnel tests which may underestimate the aerodynamic drag in the real world.

The increase in the cycle averaged drag coefficient over the zero yaw drag coefficient is largely dependent on the drag rise with yaw angle.

The aerodynamic development engineer should devote considerable effort to reducing the drag coefficient at yaw angles up to $10^{\circ}$, which would reduce the effects of the natural wind on fuel economy.

\section{References}

(1) Transport \& Environment Report; 'Mind the Gap 2015 - closing the chasm between test and real world car $\mathrm{CO}_{2}$ emissions'. European Federation for Transport and Environment, September 2015.

(2) Howell, J.P., 'Aerodynamic Drag of Passenger Cars at Yaw'. SAE 2015-01-1559, 2015.

(3) Cooper, K.R., 'Truck Aerodynamics Reborn - Lessons from the Past'. SAE 200301-3376, 2003.

(4) Windsor, S., 'Real world drag coefficient - is it wind averaged drag?'. IMechE International Vehicle Aerodynamics Conference, Loughborough University, 2014.

(5) MIRA Aerodynamic Wind Tunnel Facilities Users' Handbook.

(6) Carr, G.W., 'Aerodynamics as a Means to Fuel Economy' IMechE Transactions, C210, 1978.

(7) Meteorological Office, 'Average Wind Speeds and Deviations from the Long Term Mean'. Dec. 2015.

https://www.gov.uk/government/uploads/system/uploads/attachment_data/file/48 7867/ET_7.2.xls

(8) Davenport, A.G., 'A Rationale for the Determination of Design Wind Velocities'. J. Struct. Div., Proc. ASCE, 1960.

(9) Scruton, C.R., 'A Review of Industrial Problems related to Atmospheric Shear Flows'. AGARD CP48, Paper 23, 1969.

(10) Hucho, W-H., 'Aerodynamik der stumpfen Körper', Springer, ISBN 978-3-83481462-3, 2011

(11) Engineering Sciences Data Unit, 'Strong Winds in the Atmospheric Boundary Layer, Part 1: Mean Hourly Wind Speeds'. ESDU 82026, 1982 Amended 1993.

(12) Smith, N.P., 'Wind Gusts Measured on High Speed Roads'. MIRA Report 1972/7, 1972.

(13) Götz, H., 'Crosswind Facilities and Procedures'. SAE Surface Vehicle Information Report J1753, 1994.

(14) Richards, P.J., Fong, S., Hoxey, R.P., 'Anisotropic Turbulence in the Atmospheric Boundary Layer'. Jnl of Wind Engineering and Industrial Aerodynamics, Vol. 71, 1997.

(15) Cooper, K.R., 'A Wind Tunnel Investigation into the Fuel Savings Available from the Aerodynamic Drag Reduction of Trucks'. DME/NAE Quarterly Bulletin 1976(3). National Research Council of Canada, 1976. 
(16) Früh, W-G., 'From Local Wind Energy Resource to National Wind Power Production'. AIMS Energy, Vol. 3, Issue 1, 2015.

(17) Department for Transport, 'Road Traffic Estimates: Great Britain 2014'. May 2015.

(18) Meteorological Office. 'Virtual Met Mast ${ }^{\mathrm{TM}}$ Verification Report'. June 2013.

(19) Kosmina, L., Henderson, J., 'Wind data for SAP2012'. 2011

(20) Howell, J.P., Panigrahi, S., 'The Effect of Drag Rise at Yaw on the WindAveraged-Drag Coefficient for Passenger Cars'. Advanced Automotive Aerodynamics, Internect Conference, Bentley, June 2015.

(21) Howell, J., Forbes, D., Passmore, M., Page, G., 'The Effect of a Sheared Crosswind Flow on Car Aerodynamics'. To be published, SAE 2017.

(22) Howell, J.P., 'Aerodynamic Drag in a Windy Environment'. IMechE International Vehicle Aerodynamics Conference, Loughborough University, 2014.

(23) Howell, J.P., Newnham, P., Passmore, M.A., 'Effect of Free Stream Turbulence on Road Vehicle Aerodynamics'. Progress in Vehicle Aerodynamics and Thermal Management 5, FKFS Stuttgart, ISBN 978-3-8169-2771-6, 2007. 


\section{Appendix 1}

\section{Notation}

$\begin{array}{ll}c & \text { Weibull scale factor } \\ C_{D} & \text { Drag coefficient } \\ C_{D 0} & \text { Drag coefficient at } 0^{\circ} \text { yaw } \\ C_{D W} & \text { Wind averaged drag coefficient } \\ C_{D W C} & \text { Cycle averaged drag coefficient } \\ k & \text { Weibull shape factor } \\ P & \text { Probability } \\ P_{A} & \text { Aerodynamic drag power } \\ t & \text { Time } \\ T & \text { Total cycle time }- \text { excluding stops } \\ U_{R} & \text { Resultant velocity } \\ U_{V} & \text { Vehicle velocity } \\ U_{W} & \text { Wind velocity } \\ U_{W G} & \text { Gradient wind velocity } \\ U_{W M} & \text { Mean wind velocity } \\ z & \text { Height above ground } \\ z_{G} & \text { Gradient height }- \text { atmospheric boundary layer } \\ z_{0} & \text { Terrain roughness parameter } \\ \alpha & \text { Wind profile exponent } \\ \Gamma & \text { Gamma function } \\ \Phi & \text { Wind angle } \\ \Psi & \text { Yaw angle }\end{array}$

Appendix 2

\section{Abbreviations}

HB

MPV

NB

SUV

WLTC

WLTP
Hatchback (Small)

Multi Purpose Vehicle (People Carrier)

Notchback

Sport Utility Vehicle

Worldwide Harmonized Light Vehicle Test Cycle

Worldwide Harmonized Light Vehicle Test Procedure 
Appendix 3

Table A3. Vehicle Dimensions

\begin{tabular}{|c|c|c|c|c|}
\hline Car & L (m) & W (m) & H (m) & $\mathbf{A ~}^{\left(\mathbf{m}^{\mathbf{2}}\right)}$ \\
\hline MPV 1 & 4.64 & 1.84 & 1.63 & 2.62 \\
\hline MPV 2 & 4.28 & 1.75 & 1.63 & 2.41 \\
\hline MPV 3 & 4.14 & 1.72 & 1.60 & 2.40 \\
\hline MPV 4 & 4.62 & 1.81 & 1.73 & 2.73 \\
\hline MPV 5 & 4.76 & 1.79 & 1.64 & 2.53 \\
\hline MPV 6 & 4.32 & 1.71 & 1.86 & 2.70 \\
\hline MPV 7 & 4.75 & 1.80 & 1.78 & 2.81 \\
\hline SH 1 & 3.97 & 1.72 & 1.50 & 2.18 \\
\hline SH 2 & 3.94 & 1.71 & 1.49 & 2.21 \\
\hline SH 3 & 4.03 & 1.69 & 1.49 & 2.20 \\
\hline SH 4 & 4.05 & 1.72 & 1.46 & 2.16 \\
\hline SH 5 & 3.96 & 1.74 & 1.46 & 2.14 \\
\hline SH 6 & 3.85 & 1.70 & 1.51 & 2.20 \\
\hline SH 7 & 3.97 & 1.68 & 1.46 & 2.09 \\
\hline SUV 1 & 4.39 & 1.80 & 1.76 & 2.63 \\
\hline SUV 2 & 4.50 & 1.82 & 1.73 & 2.63 \\
\hline SUV 3 & 4.51 & 1.76 & 1.68 & 2.52 \\
\hline SUV 4 & 4.61 & 1.82 & 1.86 & 2.80 \\
\hline SUV 5 & 4.58 & 1.78 & 1.71 & 2.55 \\
\hline SUV 6 & 4.74 & 1.88 & 1.66 & 2.65 \\
\hline SUV 7 & 4.57 & 1.85 & 1.67 & 2.60 \\
\hline NB 1 & 4.92 & 1.87 & 1.46 & 2.30 \\
\hline NB 2 & 4.71 & 1.85 & 1.39 & 2.23 \\
\hline NB 3 & 5.07 & 1.90 & 1.48 & 2.48 \\
\hline NB 4 & 4.58 & 1.77 & 1.45 & 2.20 \\
\hline NB 5 & 4.83 & 1.86 & 1.50 & 2.37 \\
\hline NB 6 & 4.47 & 1.74 & 1.42 & 2.06 \\
\hline NB 7 & 4.73 & 1.81 & 1.43 & 2.17 \\
\hline
\end{tabular}


